\title{
Micromorfología de la capa híbrida de dos sistemas adhesivos. Análisis al MET
}

\section{Hibrid layer micromorphology of two adhesive systems. TEM analysis}

Valenzuela Aránguiz V*, García González D**, Zamorano Pino X***

\section{RESUMEN}

Numerosos estudios evidencian que existen diferencias micromorfológicas entre los sistemas adhesivos monocomponentes y autograbantes. Con el objetivo de comparar la micromorfología de la Capa Híbrida de ambos sistemas, mediante observación al microscopio electrónico de transmisión (MET), se prepararon cavidades en seis premolares en dentina de mediana profundidad. A tres se les aplicó un sistema convencional monocomponente, y en tres se utilizó un sistema adhesivo autograbante. La capa híbrida formada por el sistema autograbante presentó un patrón regular, más delgado y homogéneo que la formada por el sistema adhesivo convencional. Los grosores promedio de esta estructura fueron de $1 \mu \mathrm{m}$ y $2 \mu \mathrm{m}$ respectivamente.

Palabras clave: Micromorfología capa híbrida, MET, adhesivo convencional mono componente, adhesivo autograbante.

\section{SUMMARY}

Numerous studies show differences in micromorfological aspects between self-etchings and conventional adhesive systems. Dentin cavities were performed on 6 premolars to compare Micromorphology of the hybrid layer between both systems. One three of them self-etching system was applied, on the other three, the monocomponent conventional system.

The hybrid layer formed by the self-etching system showed a regular pattern, thinner and more homogenous than the one formed by the conventional system. The average thickness of the structure was 1 ìm and 2 ìm respectively.

Key words: Micromorphology hybrid layer, TEM, conventional adhesive system, self-etching adhesive system.

Fecha de recepción: 15 de febrerode 2011.

Aceptado para publicación: 25 de abril de 2011.

Valenzuela Aránguiz V, García González D, Zamorano Pino X. Micromorfología de la capa híbrida de dos sistemas adhesivos. Análisis al MET. Av. Odontoestomatol 2012; 28 (3): 133-140.

* Profesor Titular. Asignatura Odontología Integral del Adulto. Facultad de Odontología. Universidad Mayor. Chile.

** Cirujano Dentista. Práctica Privada.

*** Profesor Asistente. Asignatura Odontología Integral del Adulto. Facultad de Odontología. Universidad Mayor. Chile. 


\section{INTRODUCCIÓN}

A partir de estudios de la composición y microanatomía de los tejidos duros así como de la fisiología del complejo dentino pulpar se han podido desarrollar nuevas técnicas y nuevos adhesivos que han ido perfeccionando la unión de los materiales restauradores al tejido dentario. A pesar de ello, los objetivos de los nuevos adhesivos siguen siendo los mismos que perseguía Buonocuore en los años cincuenta (1) y que se resumen fundamentalmente en dos:

1. Conseguir una unión resistente y duradera del material restaurador al diente.

2. Conseguir un sellado eficiente en la interfase diente-restauración.

Al realizar una correcta técnica adhesiva los monómeros de resina penetran por los nano espacios que quedan entre los manojos de fibras colágeno, previamente expuestos por la acción ácida en la superficie dentinaria, y que al polimerizar quedan atrapadas en ella, conformando una estructura mixta denominada Capa Híbrida. (2) El rol de esta estructura es fundamental para lograr los objetivos antes mencionados y la importancia cuantitativa en la fuerza de unión a dentina de los adhesivos ha sido ampliamente demostrada por diferentes estudios $(1,3)$.

La técnica adhesiva convencional se logra tras varias etapas por parte del clínico, que incluyen un grabado ácido, lavado de éste, aplicación de un primer y un adhesivo sobre dentina suficientemente húmeda, que deben ser foto polimerizados antes de agregar una resina de restauración definitiva. Con el fin de simplificar la técnica y lograr una correcta adhesión en menos tiempo, se han desarrollado los sistemas adhesivos de autograbado, es decir, en un paso clínico se logra grabar dentina y llevar la resina hacia estos nano espacios conformando las ya nombradas estructuras.

En cuanto a calidad y resistencia, los sistemas de autograbado presentan aún controversias, ya que para algunos clínicos los resultados obtenidos no han sido satisfactorios, atribuyendo este problema a diferencias en la capa híbrida de estos sistemas respecto a los sistemas convencionales (4).

El propósito de este trabajo es confrontar dos sistemas adhesivos, uno convencional mono componen- te y otro sistema adhesivo autograbante, describiendo al Microscopio Electrónico de Transmisión (MET) la micromorfología de la capa híbrida, comparando grosor y homogeneidad de esta estructura.

\section{MATERIAL Y MÉTODO}

Para este estudio se prepararon 7 premolares extraídos por indicación ortodóncica a dos pacientes de 10 años de edad. Estos premolares estaban sanos en boca. Una vez hechas las exodoncias se mantuvieron en suero fisiológico, aproximadamente una semana, hasta el momento de la preparación de la muestra. Fueron divididos al azar en dos grupos de tres dientes y un diente control. Se realizaron cavidades en oclusal a un milímetro del límite amelo-dentinario con el objetivo de exponer dentina en su parte media. Para esto se utilizó turbina y fresas cilíndricas de alta velocidad.

\section{Grupo 1}

En este primer grupo se aplicó la técnica de grabado total. Esto consiste en la aplicación de ácido fosfórico al $37 \%$, durante un período de 15 segundos, sobre esmalte y dentina simultáneamente. Una vez transcurrido este tiempo, se procedió a lavar con abundante agua para eliminar los restos de ácido de la preparación cavitaria y se secó suavemente la dentina hasta que tuviera un aspecto húmedo (técnica húmeda). Luego se aplicó un adhesivo convencional monocomponente (Single Bond-3M-Espe), en dos capas. Posteriormente se aplicó la resina compuesta de restauración Filtex Z 350 (3M-Espe), siguiendo rigurosamente los pasos estipulados por el fabricante. Se concluyó polimerizando por el tiempo requerido.

\section{Grupo 2}

En este grupo se aplicó un sistema de autograbado (One Coat SE Bond), siguiendo las indicaciones del fabricante. Se aplicó el primer con una micro brocha (proporcionada por el fabricante) durante 30 segundos sobre la superficie dentinaria. Con aire leve se secó la superficie para luego aplicar el bond 
durante 20 segundos con una microbrocha distinta. Se sopló levemente y se procedió a polimerizar por 30 segundos. Posteriormente se aplicó la resina compuesta de restauración Filtex Z 350 (3MEspe).

\section{Control}

Solamente se hicieron cortes de este tejido dentinario para visualizar dentina sana sin intervención adhesiva.

Una vez terminada esta etapa las muestras fueron enviadas al laboratorio donde se prepararon con el siguiente protocolo, para observarlas en el MET:

1. Descalcificación: tratamiento con ácido fórmico $10 \%$ con agitación durante 48 horas.

2. Después de lavado, se deshidrató en acetonas de concentración ascendentes

3. Posteriormente se embebieron las muestras en EPON 812, para realizar los cortes

4. Las secciones se realizaron en un ultra micrótomo Porter-Blum y se contrastaron con doble tinción de uranilo y plomo.

Las observaciones se realizaron a diferentes aumentos con el microscopio electrónico Zeiss EM-109 de la Unidad de Microscopía Electrónica-Cesat, Facultad de Medicina, Universidad de Chile.

\section{RESULTADOS}

Microfotografías representativas, tomadas en el MET a distintos aumentos, ilustran el tejido dentinario sin tratamiento (Control) (Figs. 1-3) y la interfase entre dentina y los dos adhesivos en estudio (Figs. 4-9).

La dentina que fue expuesta y no recibió tratamiento adhesivo muestra una disposición de los manojos colágenos en variadas direcciones, llegando éstos a la superficie. Zonas electrón lúcidas son apreciadas entre esta trama colágena, que representa la porción mineralizada del tejido dentinario que ha dejado estos espacios debido al tratamiento de descalcificación de la muestra. Los túbulos dentinarios se aprecian parcialmente vacíos, con tejido orgánico en su interior que podría ser remanente odontoblástico, con

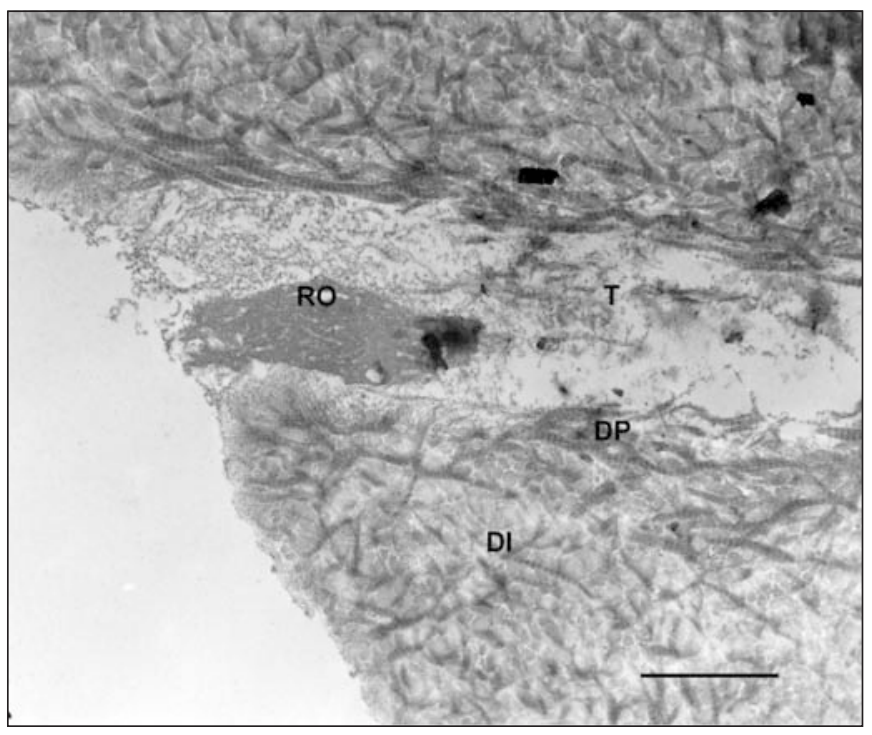

Fig. 1. Con aumento de 12.000x. Túbulo dentinario (T) con remanente odontoblástico $(\mathrm{RO})$ y otros restos orgánicos. Dentina intertubular (DI) con manojos de colágeno en todas direcciones. $\mathrm{DP}=$ dentina peritubular. Barra $=3 \mu \mathrm{m}$.

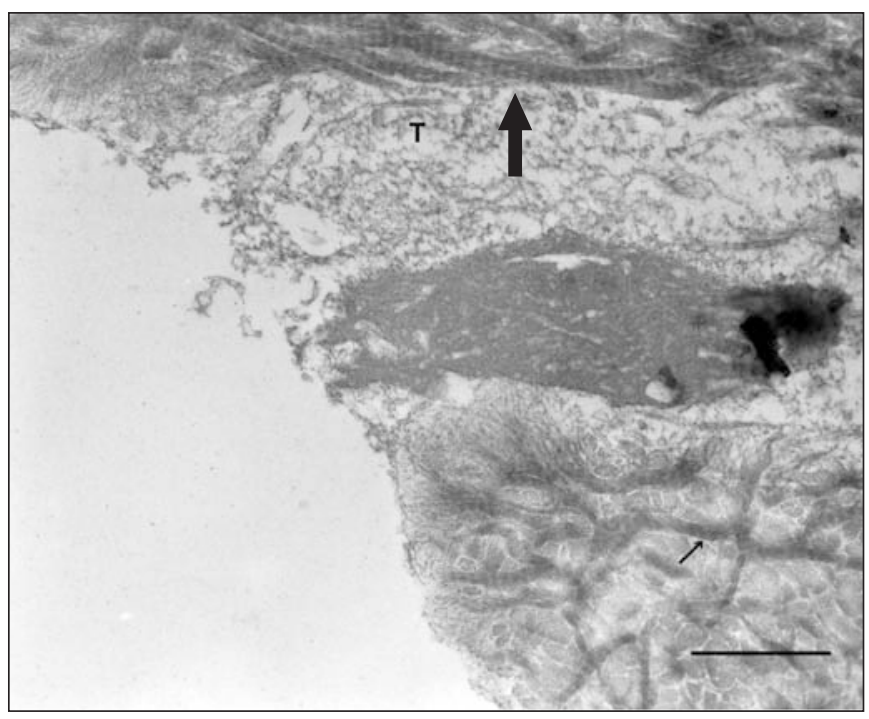

Fig. 2. Flecha negra indica manojo de colágeno cortado longitudinalmente. Estos manojos llegan hasta la superficie. Microfotografía tomada a 20.000x. Barra $=2 \mu \mathrm{m}$.

un diámetro promedio de $4 \mu \mathrm{m}$. A mayor aumento se aprecia claramente las estriaciones características del colágeno tipo I.

La dentina en que se aplicó sistema adhesivo convencional (Figs. 4-6), agrega en su superficie una fase de polímero adhesivo imbricado íntimamente 


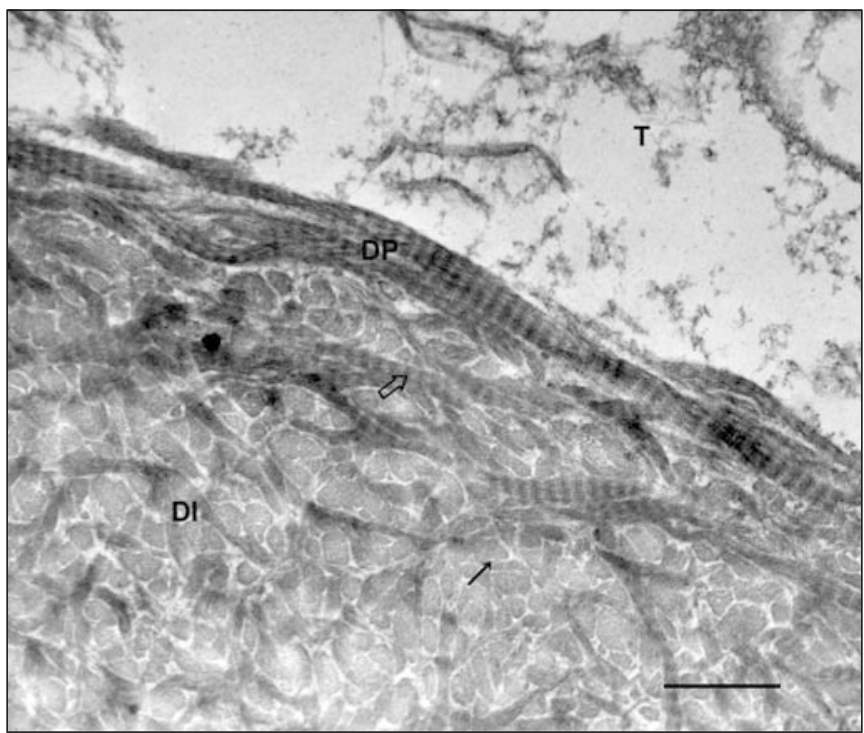

Fig. 3. A un aumento de 30.000x. Estriaciones características de colágeno tipo I. Se observan manojos de colágeno cortados en sentido transversal y en sentido longitudinal. $\mathrm{DI}=$ dentina intertubular. $\mathrm{DP}=$ dentina peritubular. Barra $=1 \mu \mathrm{m}$.

con la trama colágena. Este entrelazado es la denominado capa híbrida, que es irregular y poco homogéneo. Promedia $2 \mu \mathrm{m}$ de espesor, alcanzando hasta $3 \mu \mathrm{m}$ en algunas zonas y $1,5 \mu \mathrm{m}$ en otras. Cuando el

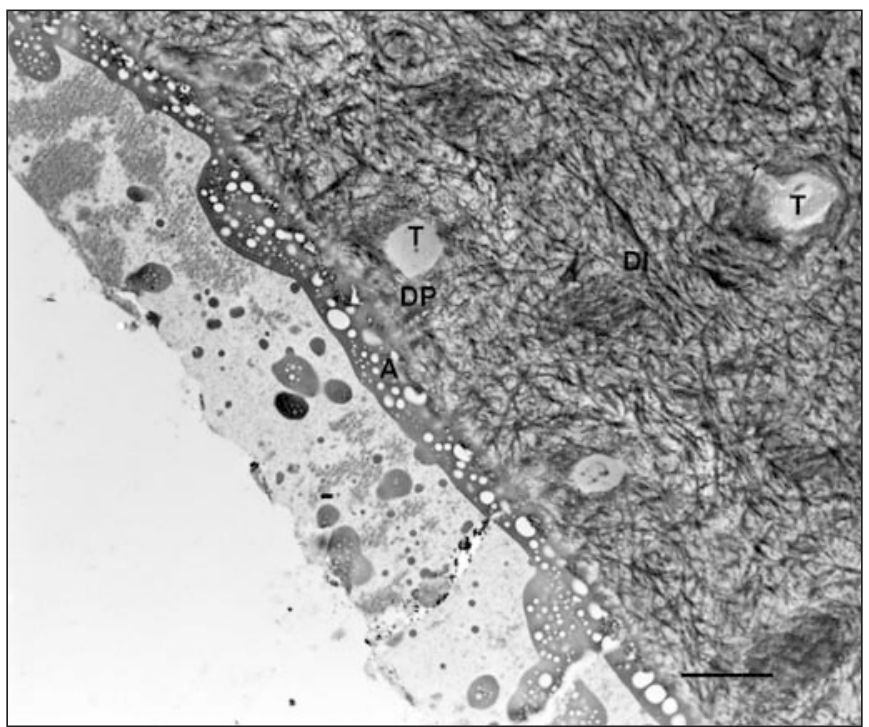

Fig. 4. Panorámica a 4.400x con sistema adhesivo convencional. Túbulos dentinarios ( $\mathrm{T}$ ) cortados en sentido transversal y típica disposición colágena tanto en dentina intertubular (DI) como peritubular (DP). Fase adhesiva (A) irregular con múltiples espacios electrón lúcidos que pueden deberse al exceso de humedad al preparar la muestra. Barra $=6 \mu \mathrm{m}$.

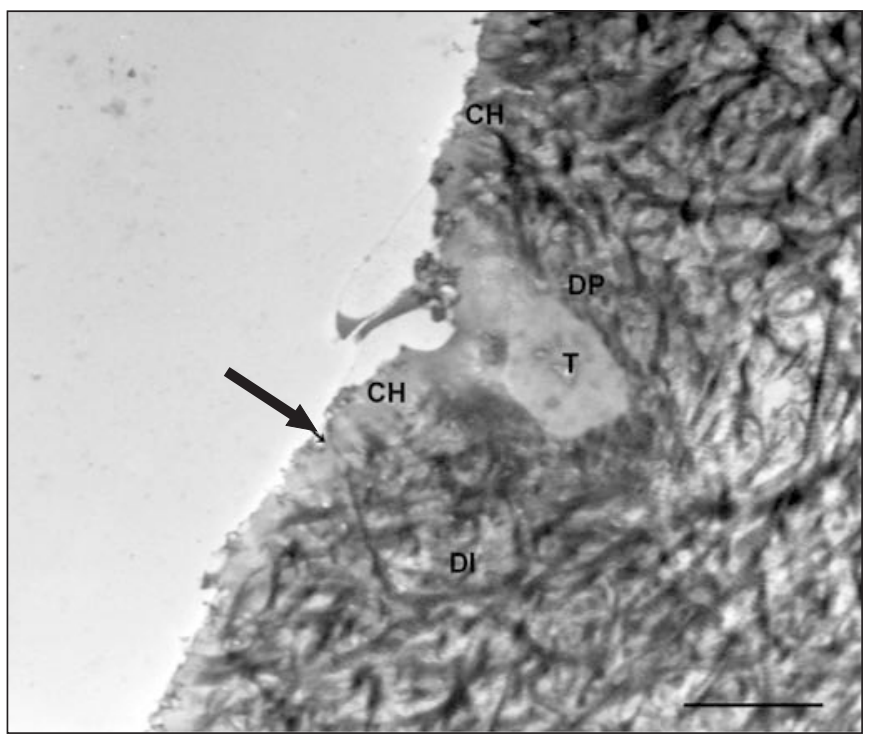

Fig. 5. 12.000x. Tag de resina (T) cortado en sentido oblicuo. La misma resina continúa hacia la superficie formando la capa híbrida

$(\mathrm{CH})$. Flecha negra indica los manojos de colágeno que desde las profundidades llegan a la superficie para entrelazarse con el adhesivo. $\mathrm{DI}=$ dentina intertubular. $\mathrm{DP}=$ dentina peritubular. Barra $=3 \mu \mathrm{m}$.

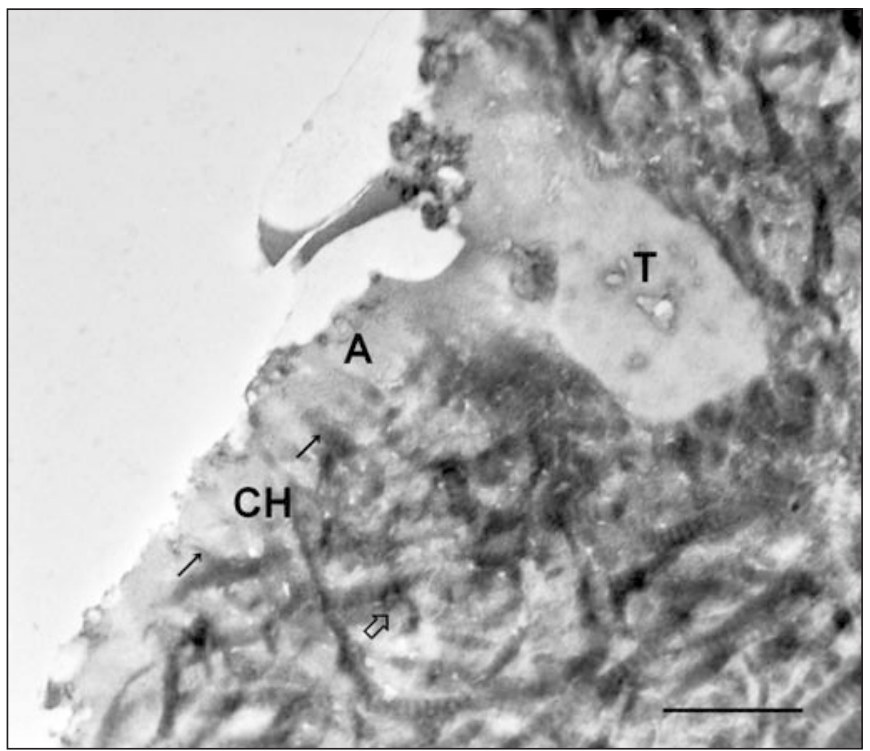

Fig. 6. Microfotografía a 20.000x. Se aprecian los manojos de colágeno imbricándose con el adhesivo formando la capa híbrida $(\mathrm{CH}) . \mathrm{T}=$ Tag de resina. $\mathrm{A}=$ adhesivo. Barra $=2 \mu \mathrm{m}$.

adhesivo penetra por el túbulo dentinario forma los tags de resina. El túbulo, cortado en sentido oblicuo, presenta un contenido que tiene la misma electrón densidad que el material depositado en la superficie dentinaria que forma la capa híbrida. La dentina 
mantiene su micromorfología, disponiendo los manojos de colágeno en distintas direcciones (longitudinales, transversales y oblicuos).

En el sistema de autograbado se pueden distinguir tres fases (Figs. 7-9); una zona que cumple con la micromorfología dentinaria típica, otra zona que es más electrón densa y que corresponde a la capa híbrida, y por último, una zona homogénea, más electrón lúcida que la anterior, que corresponde al adhesivo. La capa híbrida es más homogénea y regular en su espesor, presentando un promedio de 1 $\mu \mathrm{m}$, con una variación de $\pm 0,3 \mu \mathrm{m}$.

\section{DISCUSIÓN}

Pocos estudios son concluyentes respecto a los nuevos sistemas de autograbado. Aún no se ha logrado incorporar éstos a la práctica clínica diaria, a pesar de los avances que han tenido en los últimos años. Nuestro estudio muestra que a pesar de haber diferencias en el grosor de la capa híbrida, existen otros factores que actuarían en desmedro de los sistemas adhesivos convencionales, como el control de hu-

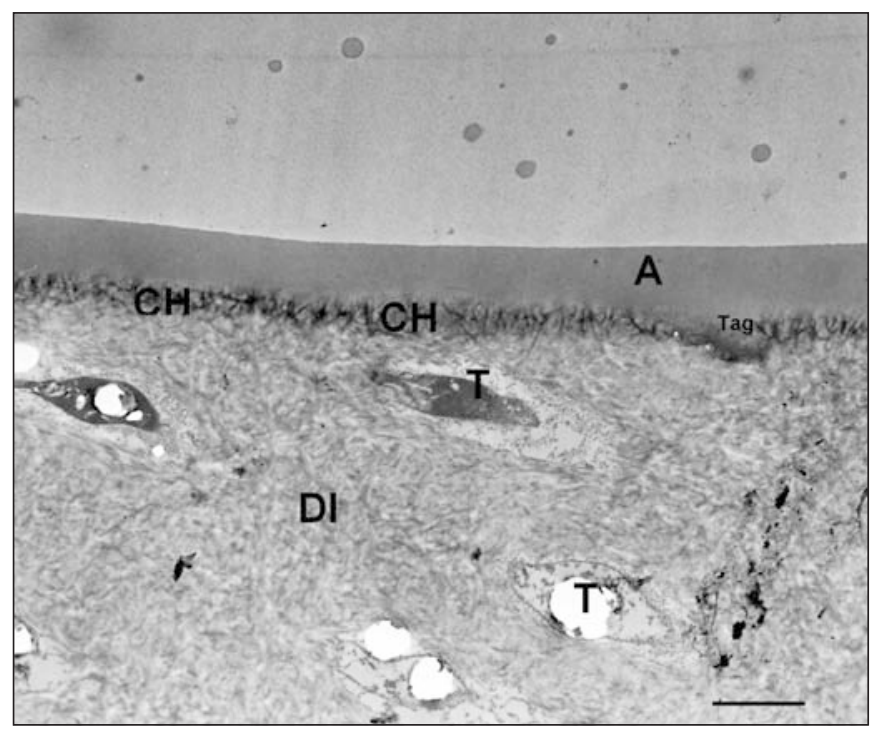

Fig. 7. Microfotografía panorámica a 4.400x del sistema adhesivo de autograbado. Tres fases distinguibles. La primera por dentina en su disposición característica (DI). Superior e íntimamente relacionada con esta está la capa híbrida $(\mathrm{CH})$ que es más electrón densa. Por último está la fase adhesiva (A) que es homogénea. Túbulos dentinarios (T) cortados en sentido transversal y oblicuo. En parte superior derecha se insinúa un Tag. Barra $=6 \mu \mathrm{m}$.

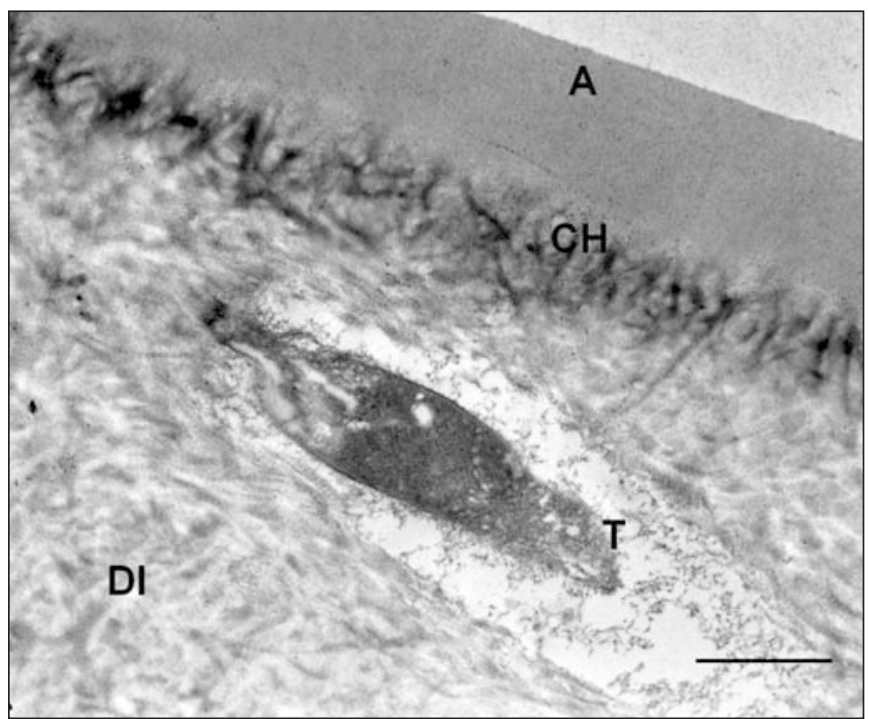

Fig. 8. 12.000x. Túbulo dentinario (T) con remanente orgánico en su interior. Dentina intertubular con múltiples manojos colágenos. Clara imbricación entre la trama colágena y el adhesivo (A) que forman la capa híbrida $(\mathrm{CH})$. Barra $=3 \mu \mathrm{m}$.

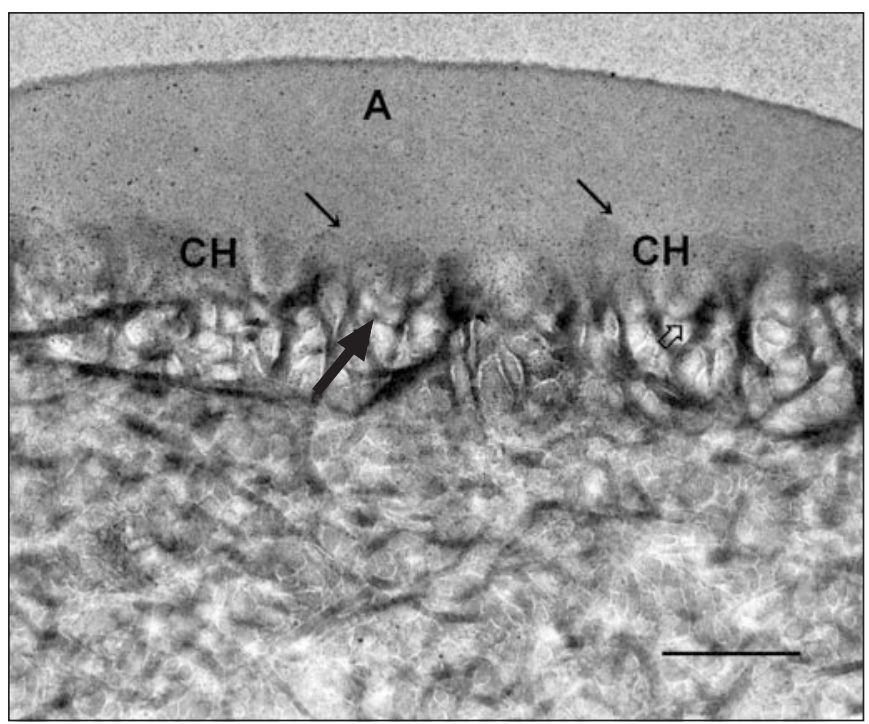

Fig. 9. 20.000x. Flechas negras indican hasta qué profundidad penetró el adhesivo (A). En este caso la capa híbrida $(\mathrm{CH})$ tiene un espesor promedio de $1 \mu \mathrm{m}$. Barra $=2 \mu \mathrm{m}$.

medad en dentina expuesta reflejado en porosidades observables en el estrato adhesivo.

Luego de la aplicación del ácido, es necesario lavar la superficie dentinaria, para así dejar expuestas las fibras colágenas y luego eliminar el agua residual, lo cual representa una de las variables más difíciles de 
manejar, debido a la dificultad para estandarizar clínicamente la humedad óptima de la dentina, antes de la aplicación del adhesivo, para prevenir el colapso y desnaturalización superficial de la malla colágena. $(5,6)$ Este último fenómeno explicaría las porosidades que se observaron en las microfotografías de sistemas adhesivos convencionales. Esta separación entre la capa híbrida y la resina compuesta podría significar que, en el caso de los sistemas de autograbado, la unión entre la capa híbrida y la resina es más fuerte que con los adhesivos mono componentes, pero este supuesto exige mayor investigación.

Por otro lado, luego de aplicar ácido fosfórico sobre la superficie dentinaria, éste va actuando cada vez menos, ya que se neutraliza por el efecto buffer de la dentina (4) y por ser hipertónico. (7) Por lo tanto, la última zona de dentina sobre la que actúa, estará pobremente grabada y en consecuencia, será escasamente infiltrada por el adhesivo, indicando que la capa híbrida que se forma a ese nivel será irregular y débil, lo que se traduce en un mal sellado y riesgo de sensibilidad postoperatoria. Con los sistemas adhesivos mono componentes, se forman tres zonas dentro de la capa híbrida, lográndose sólo en la zona media una capa híbrida de buena calidad. Con los adhesivos de autograbado, en cambio, se forma una sola, más delgada, compacta, saturada con monómeros y homogénea lo que explicaría los valores de retención encontrados al usar estos sistemas adhesivos $(1,8,9)$.

En concordancia con los trabajos de Pecora (2002) (3), Hanning $M$ et al (2001) (4), Nakajima $M$ et al (1999) (6) y Ferrari M et al (1996) (11), quienes también realizaron estudios con sistemas de autograbado sobre dentina sana, nuestras observaciones al MET, muestran que la capa híbrida obtenida con los sistemas adhesivos de autograbado es bastante homogénea, pero muy delgada, alcanzando grosores de sólo $1 \mu \mathrm{m}$. Esta homogeneidad se debe a que estos sistemas de autograbado previenen la desestabilización del colágeno, ya que se evita la excesiva acidificación, el sobre mojado y sobre secado de la dentina. Además no quedan espacios inertes, ya que la desmineralización e infiltración de la resina ocurren simultáneamente.

El menor grosor de la capa híbrida obtenida con los sistemas autograbantes, en comparación con los adhesivos mono componentes, se debe a que la penetración en dentina es más autolimitada con estos productos, ya que como el primer no se lava, sino que sólo se seca con aire, los iones de calcio y fosfato que fueron solubilizados de los cristales de hidroxiapatita, deben estar suspendidos en la solución acuosa del primer, por lo tanto, cuando el agua se evapora, las concentraciones de calcio y fosfato presentes en los espacios interfibrilares, pueden exceder la constante de solubilidad para un cierto número de sales de fosfato de calcio y presumiblemente, estos minerales precipitan como partículas de calcio amorfo dispersas entre la capa de resina infiltrada como una suspensión coloidal, lo que tendería a limitar la disolución de la apatita, determinando un límite en la profundidad de desmineralización. Además, la capacidad buffer de la dentina, el foto curado del primer y la subsecuente aplicación del agente de unión, pueden restringir e inhibir los efectos autograbantes de las moléculas del primer (12).

Otro factor que podría explicar el menor grosor de la capa híbrida es que el $\mathrm{pH}$ de estos sistemas es mayor. Al ser menos ácido que el ácido fosfórico ( $\mathrm{pH}$ 0.8 ), descalcifican la dentina significativamente menos: 1.0 micrón v/s 8.1 micrones en los sistemas mono componentes. De este modo, se expone menos colágeno y la resina humedece y sella completamente la dentina, creando una capa híbrida delgada, pero uniforme y homogénea. Además, mientras se efectúa el grabado, el pH de los ésteres fosfóricos se eleva debido a la neutralización de los monómeros ácidos por el efecto buffer de la dentina, deteniéndose la reacción de desmineralización.

Uribe et al (2004) (7), en su estudio, obtuvo los siguientes grosores de capa híbrida; convencional 4,8 $\mu \mathrm{m}$ y autograbantes $4,3 \mu \mathrm{m}$. En contraposición a esto, en nuestro estudio, obtuvimos valores de 2 $\mu \mathrm{m}$ para sistemas convencionales y $1 \mu \mathrm{m}$ para sistemas de autograbado. Esto a pesar de que el sistema de autograbado era de la misma marca y se siguieron las mismas indicaciones del fabricante. Estas diferencias podrían atribuirse a que Uribe et al (2004) (7) realizó las observaciones bajo MEB, a menos magnitud, no obteniendo límites claros de la hibridación. Otra explicación sería que, al requerir la muestra ser desmineralizada para su observación al MET, las fibras colágenas pierden el soporte 
mineral, colapsándose y disminuyendo sus dimensiones reales.

Según Blunck et al (2002) (9), el grosor de la capa adhesiva es un factor secundario en los sistemas autograbantes, porque su mecanismo de adhesión principal se basa en la disolución, transformación e incorporación del barro dentinario y en la interacción molecular entre la hidroxiapatita remanente y el monómero adhesivo, sin embargo para aumentar el grosor de esta capa híbrida, algunos investigadores han propuesto la adición de nano partículas a estos adhesivos, aunque no existen muchos estudios al respecto.

Es imposible dilucidar en este estudio el grado de desmineralización dentinaria que proporciona cada sistema adhesivo, ya que la muestra es previamente desmineralizada en su totalidad. Breschi et al (2003) (13) y T. Nikaido et al (2009) (14), plantearon, con respecto a este punto, que el sistema adhesivo, a través de sus monómeros, no es capaz de imprimar la zona de dentina desmineralizada por los ácidos o dentina muerta en toda su extensión. El ácido fosfórico penetraría en dentina $25 \mu \mathrm{m}$ y el adhesivo sólo sería capaz de imprimar 4,5 $\mu \mathrm{m}$. Estos valores muestran un grosor de capa híbrida en sistemas convencionales muy superior al encontrado en nuestro estudio.

Nakabayashi, N et al (1982) (2) mencionó que con profundidades de desmineralización de 1-2 $\mu \mathrm{m}$ son suficientes para conseguir cifras de adhesión adecuadas y puedan infiltrarse más fácilmente que desmineralizaciones más profundas. De esta manera con las cifras de hibridación obtenidas en nuestro estudio, al obtener esas profundidades de desmineralización, se consigue que la capa híbrida se forme en todo el espesor desmineralizado, no dejando espacios muertos. Según Gordan et al (1998) (15), los sistemas autograbantes no solamente simplifican la técnica clínica, sino que también disminuyen la sensibilidad de la técnica en comparación con los sistemas convencionales.

Entre otras ventajas de estos sistemas se cuentan; la desmineralización e infiltración de resina simultáneamente, permite controlar la evaporación del solvente manteniendo estable la composición del adhesivo, adecuada interacción monómero - colágeno, efectivo desensibilizador dentinario, hace menos crítico el control de la humedad dentinaria y disminuye el riesgo de las infecciones cruzadas.

\section{CONCLUSIONES}

1. La capa híbrida formada por los sistemas convencionales mono componentes es bastante irregular, menos homogénea y de mayor grosor en comparación con la capa híbrida de los adhesivos de autograbado, la que se presenta homogénea, más regular y más delgada.

2. El grosor de la capa híbrida de sistemas adhesivos convencionales es de $2 \mu \mathrm{m}$ promedio, y la capa híbrida de sistemas adhesivos de autograbado es de $1 \mu \mathrm{m}$ promedio.

\section{BIBLIOGRAFÍA}

1. Hernández M. Aspectos prácticos de la adhesión dentina. Av. Odontoestomatol 2004; 20(1):19-32.

2. Nakabayashi N. Resin reinforced dentine due to infiltration of monomers into dentine at the adhesive interface. J Jap Soc Dent Mater Devices 1982;1:78-81.

3. Pecora N, Yaman P, Dennison J, Herrero A. Comparación of shear bond strenght relative to two testing devices. Journal of Prothetic Dentistry, 2002;88(5):511-5.

4. Hannig M, Reinhardt K, Bott B. Composite to dentin bond strength, micromorphology of the bonded dentin interface and marginal adaptation of class II composite resin restorations using Selfetching Primers, Operative Dentistry, 2001;26: 157-65.

5. Kanca J. Effect of resin primer solvents and surface wetness on resin composite bond strength to dentin. Am J Dent 1992;5:213-5.

6. Nakajima M. et al. Bonding to caries-affected dentin using self-etching primers. Am J Dent 1999;12(6):309-14. 
7. Uribe, J. Lutri, P. Sezín, M et al. Adhesión a dentina a través de distintos tratamientos del sustrato. RAOA 2004;92(4): 315-21.

8. Hannig M, Reinhardt K et al. Self-etching Primer vs Phosphoric Acid: An Alternative Concept for Composite to Enamel Bonding. Operative Dentistry 1999 24:172-80.

9. Blunck U. Adhesives: Principles and state of art. En: The silent revolution in dentistry. Carol Stream. Quintessence Int Publishing 2002;pp. 29-44.

10. Swift EJ, Perdigao J, Heymann HO. Bonding to enamel and dentin: A brief history and state of the art, 1995. Quintessence International 1995; 26(2):95-110.

11. Ferrari $M$. et al. In vivo resin.dentin interdiffusion and tag formation with lateral branches of adhesive systems. J Prosthest Dent.1996;76(3): 250-3.

12. Van Meerbeeck S, Dhem A, Goret-Nicaise $M$, Sraem M, Lambrechts P, Vanherle G.:Comparative SEM and TEM examination of the ultraestructure of the resin-dentin interdiffusion zone. J Dent Res 1993;72:495-501.

13. Breschi L, Perdigao J, Lopes, MM. et al. Morphological study of resin-dentin bonding with TEM and In-Lens FESEM. Am J Dentistry 2003; 16(4):267-74.

14. Toru Nikaido et al. Assessment of the nanostructure of acid-base resistant zone by the application of all in one adhesive systems: Super dentin formation. Bio-Medical Materials and Engineering 2009;19(2-3):163-71.

15. Gordan V, Vargas M, Cobb D. Evaluation of acidic primers in microleakage of class $\mathrm{V}$ composite resin restorations, Operative Dentistry 1998;23 (5):244-9.

\section{CORRESPONDENCIA}

Vladimir Valenzuela Aránguiz

Las Bellotas 199 oficina 75, Providencia.

Santiago de Chile.

E-mail: vladyv@vtr.net 